\title{
Ancient Cliffs and Modern Fringing Reefs: Coupling Evidence for Tsunami Wave Action
}

\author{
Tetsuya Kogure and Yukinori Matsukura
}

Additional information is available at the end of the chapter

http://dx.doi.org/10.5772/50515

\section{Introduction}

The height of a tsunami as it surges into the coasts is altered by the presence of a coral reef. In particular, wave propagation over the reef crest induces wave breaking, and energy dissipation increases to 50-90\% (Munk \& Sargent, 1948; Kono \& Tsukayama, 1980; Roberts \& Suhayda, 1983). Shibayama et al. (2005) reported that the heights of tsunamis in Sri Lanka caused by the Sumatra earthquake in 2004 were lower at coastlines with coral reefs than without. This reduction in the height of the tsunami is due to friction between the tsunami and coral reefs seaward of the coasts. Nott (1997) stated in contrast that tsunamis pass through the gaps in coral reefs; the Great Barrier Reef does not act as an effective barrier against tsunamis, since the coastline near Cairns in Australia has been impacted by tsunamis. Coral reefs are recognized as a breakwater against invading tsunamis, but details of the behavior of tsunamis around coral reefs are unknown.

Such "modern reefs" would form coastal cliffs if the reefs uplifted. Vertical limestone cliffs formed by the uplifted coral reefs are seen in tropical-subtropical areas around the world (e.g. Tjia, 1985; Maekado, 1991). The limestone cliffs, i.e., "ancient reefs", are subject to wave erosion while the "modern reefs" could control wave energy. Notches carved by the wave erosion often induce cliff collapses (Maekado, 1991; Kogure et al., 2006; Kogure and Matsukura, 2010a). Kogure et al. (2006) presented a mechanical equation for calculating the critical notch depth for cliff collapse. In addition to these cases, waves also break down or smash geomorphological environment of rocky coasts. Notched cliffs can be collapsed by waves as well as gravity (e.g. Kogure and Matsukura, 2010b). Here, one question has been raised about the relationship between the tsunami action affected by "modern" fringing reefs and cliff collapses induced by the tsunami: are there any relationships between the developments of "modern" and "ancient" fringing reefs?

We can see an interesting interaction between "modern" and "ancient" fringing reefs through tsunami wave action in Kuro-shima, a small island in the Yaeyama Islands. The Yaeyama 
Islands, in the south-western part of Japan, have been attacked by several large tsunamis in the last few thousand years (e.g. Nakata \& Kawana, 1995). The largest tsunami on record is the 1771 Meiwa Tsunami caused by the Yaeyama Earthquake of April 24, 1771. The maximum run-up height of the tsunami was estimated by Nakata \& Kawana (1995) to be more than $5 \mathrm{~m}$ on the east and south side of Kuro-shima. In Kuro-shima, a low-lying notched cliff of height 3$4 \mathrm{~m}$, made of Ryukyu Limestone, currently has a flat top surface that is partly destroyed. Many blocks, apparently due to cliff collapses, are scattered on the reef flat. Based on the observed correspondence between geometries of these blocks and the scars on nearby cliffs, the blocks have been cleaved from the cliffs. In Kuro-shima, collapses of coastal cliffs have been induced not only by enlargement of the notch at the cliff base but also by the attack of extreme waves such as tsunamis or bores during a storm (Kogure \& Matsukura, 2010a, 2010b).

The present study shows stability analysis models to evaluate the cliff collapses due to extreme waves and discusses the effects of wave heights on the cliff collapses. Finally, this paper presents the effect of coral reefs in reducing the height of extreme waves, especially tsunamis, by comparing the distribution of blocks produced by wave-induced collapses of coastal cliffs and the development of coral reefs around Kuro-shima.

\section{Study area}

Kuro-shima is a low-lying island made of uplifted coral limestone, located in the southwestern area of the Ryukyu Islands (Fig. 1). Geomorphic, geologic and lithologic features are described below.

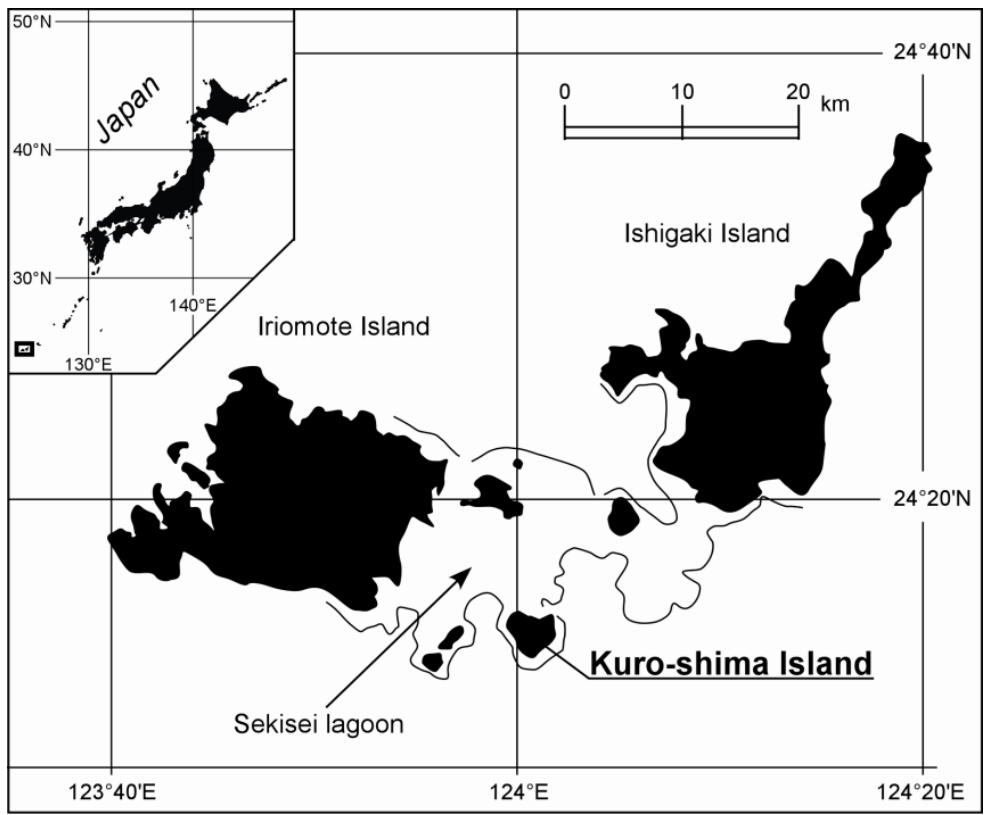

Figure 1. Location of Kuro-shima Island. 


\subsection{Geomorphological setting}

The Pleistocene coral limestone is known as Ryukyu Limestone. The circumference of the island is about $10 \mathrm{~km}$, and its highest point is about $10 \mathrm{~m}$ above mean sea level. Fringing reefs have developed around the island, except for the northern part; the coral reefs that are developing at the north of the island meet a large lagoon. Coastal areas in the south-east and south-west areas of the island face the Pacific Ocean. The maximum and minimum distance from the coast to the offshore reef edge is about $850 \mathrm{~m}$ in the south-east and $200 \mathrm{~m}$ in the south-west (Fig. 2). Waves break at the reef edge at low tide, and reach the coastal cliffs at high tide. A fault running NW-SE has developed in the north-eastern part of the island, and development of the coral reef is discontinuous along an extension of the fault (Fig. 2). A range of coastal cliffs, $6 \mathrm{~km}$ long and less than $5 \mathrm{~m}$ high (Fig. 3a), has developed in the area, except at the northern sandy beaches (Fig. 2). A reef flat has developed in front of the coastal cliff. The seaward side of the reef flat is a lagoonal environment, with depth of water 1-3 m (Fig. 3b).

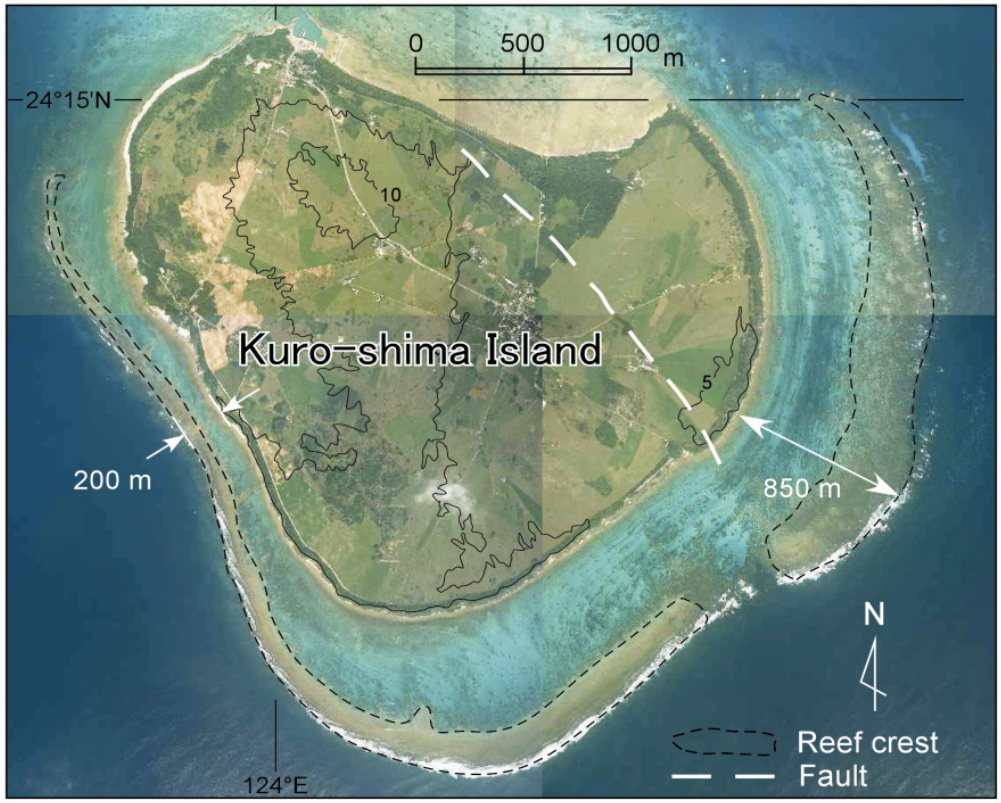

Figure 2. Photograph of Kuro-shima Island from the air. Fringing reefs are surrounded by the black dotted line. The fringing reefs are wider in the south-eastern part of the island. The fringing reefs are cut in the south-eastern part by a fault running NW-SE.

There is no visible vegetation on the top surface of the coastal cliff, certainly not near the shore. The cliff has a notch at its base; this notched cliff has a visor extending seaward (Fig. $3 b)$. The depth of the notch, defined as the horizontal distance of the visor from the retreat point of the notch to the seaward end of the visor, is 3-4 $\mathrm{m}$ at most sites. The elevation of the 
retreat point of the notch is almost exactly equal to the maximum sea level (HSL) at spring tide, which is about $1 \mathrm{~m}$ higher than mean sea level (MSL); see Fig. $3 \mathrm{~b}$.

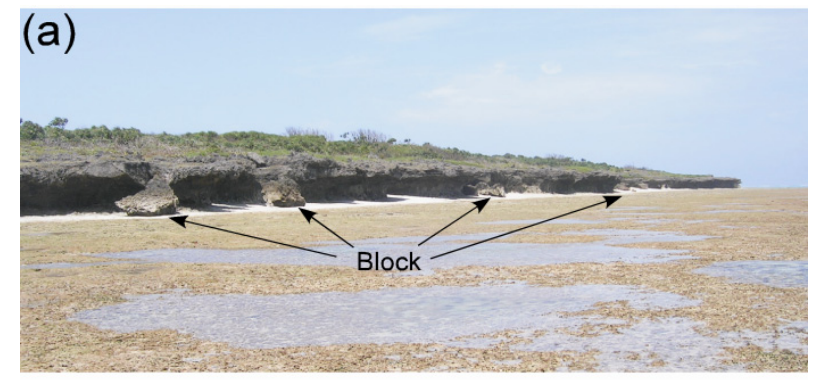

\section{(b)}

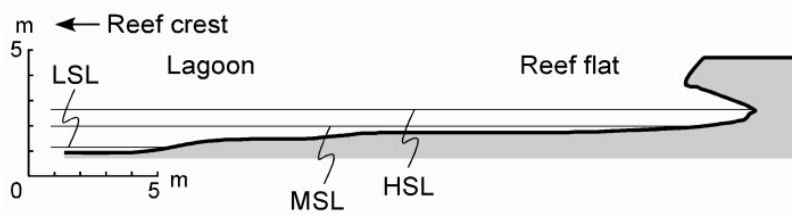

Figure 3. Coastal cliffs at Kuro-shima (Kogure \& Matsukura, 2010a). (a) Overview of coastal cliffs and fallen blocks. The cliffs are less than $5 \mathrm{~m}$ high. The picture was taken at low tide. (b) Typical profile of a coastal cliff. There is no vertical exaggeration $(x: y=1: 1)$.

Vertical joints with cracks having width between ten and several tens of centimetres have developed on coastal cliffs or reef flats. These joints appear to develop systematically rather than randomly, so that they are believed to have come about by geological processes. The depth of a joint is usually large enough to incise both cliffs and reef flats (Fig. 4a). These joints intersect coastal cliff faces at various angles, perpendicular, oblique (Fig. 4b) or parallel to the cliff. A cliff bounded by vertical joints therefore appears to be separated from the main cliff. The degree of development of a horizontal bedding plane on a cliff face varies from area to area; cliffs with and without bedding planes are distributed along the rocky coasts of this island with no apparent pattern.

\subsection{Cliff collapses and blocks}

Many angular blocks are scattered at cliff bases, and have apparently been produced by failures of notched cliffs (Fig. 3a). Along the $6 \mathrm{~km}$ coastal cliffs, more than 150 blocks were found having one side of dimension exceeding $1 \mathrm{~m}$. The blocks are composed of Ryukyu Limestone identical to the cliffs behind the blocks. Vegetation or joints are rarely seen on the surfaces of the blocks. Some blocks can be clearly identified as having originated from the cliffs immediately behind them (Fig. 5a, 5b); the place of origin of other blocks cannot be identified because they appear to have moved. Many identifiable blocks are inclined seaward, and have a triangular or quadrangular flat surface which appears to coincide with 
the top surface of the cliff (Fig. 5a, 5b). Although the lower part of these blocks is inundated at high tide, the flat surface displays no development of a notch, as shown on the cliff. A few blocks have a breadth of $10 \mathrm{~m}$ in the direction following the shoreline; in most cases the breadth is approximately $5 \mathrm{~m}$, as shown in Fig. $5 \mathrm{a}$ and $5 \mathrm{~b}$, and the maximum thickness of the blocks is about $3 \mathrm{~m}$.
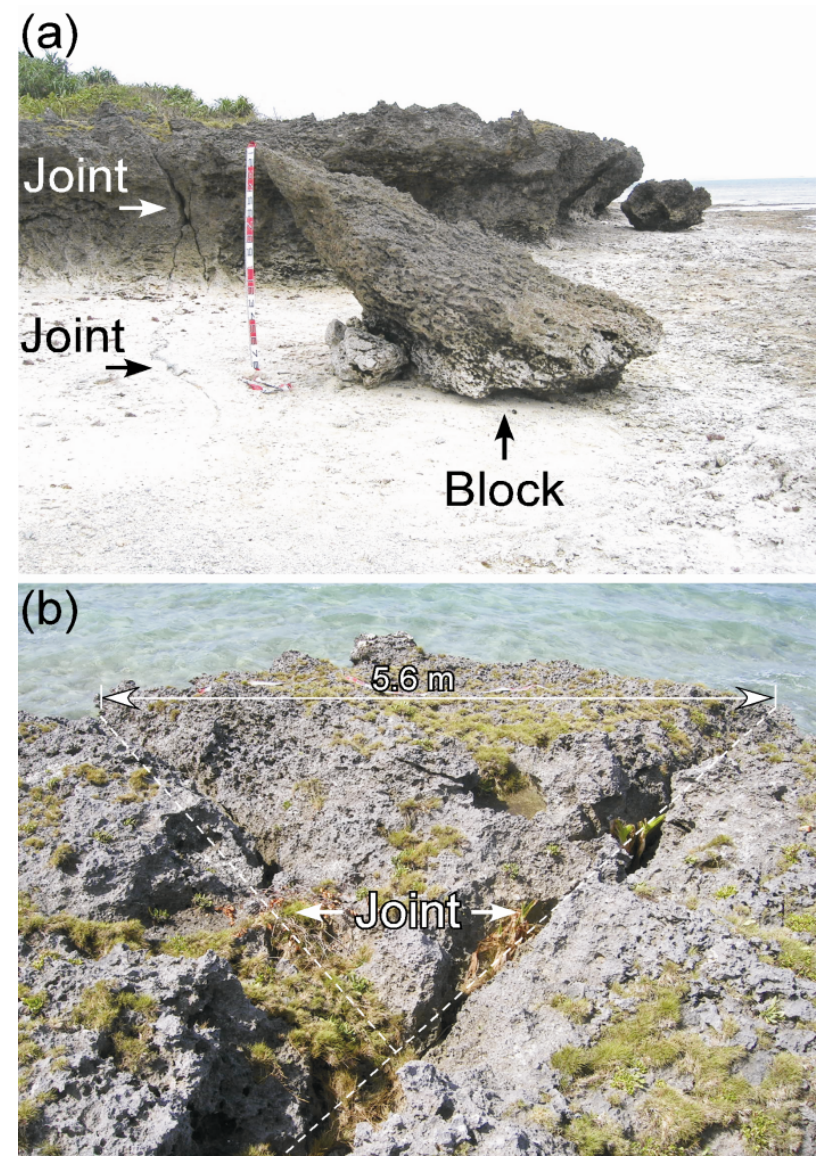

Figure 4. Cliffs with vertical joints (Kogure \& Matsukura, 2010a). (a) A vertical joint visible on coastal cliffs and reef flats. The picture was taken at low tide. (b) Example of vertical joints running oblique to the cliff face.

Some cliffs behind a fallen block show a failure scar. The shape of the scar on the cliffs corresponds to that of the block, having a triangular or quadrangular flat surface (Fig. $5 \mathrm{c}$ and 5d). Many scars have similar features, including: (1) the cliff above the retreat point of a notch has detached from the main cliff (Fig. 5b); (2) the scar consists of a nearly horizontal surface and bounding vertical surfaces (Fig. 5d), and has no sliding or shearing striation; (3) the height of the horizontal surface is almost equal to that of the retreat point of the notch; 
and (4) the vertical surfaces intersect the horizontal surface, with the vertical extension of the joints reaching the reef flat (Fig. $5 \mathrm{~b}$ and $5 \mathrm{~d}$ ). In view of the resulting visible joints on the top surface of a cliff (Fig. 4b), Kogure \& Matsukura (2010a) inferred that the vertical surfaces on the scar are joint surfaces, and that the horizontal surface is a failure surface at which cliff collapse has occurred. The cliff, which is separated from the main cliff by vertical joints, will collapse when the notch extends sufficiently far inward from the sea.

(a)
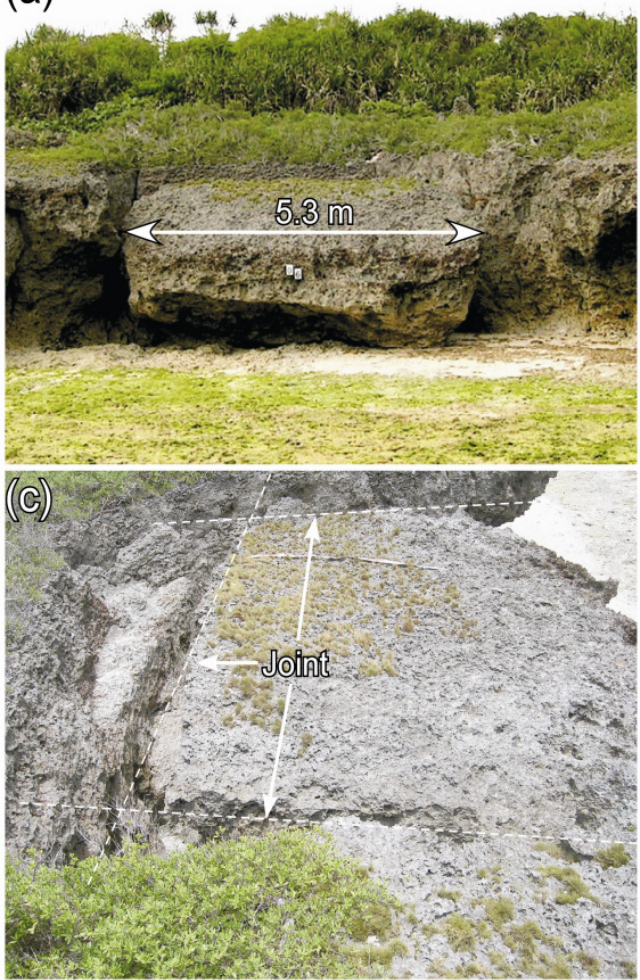
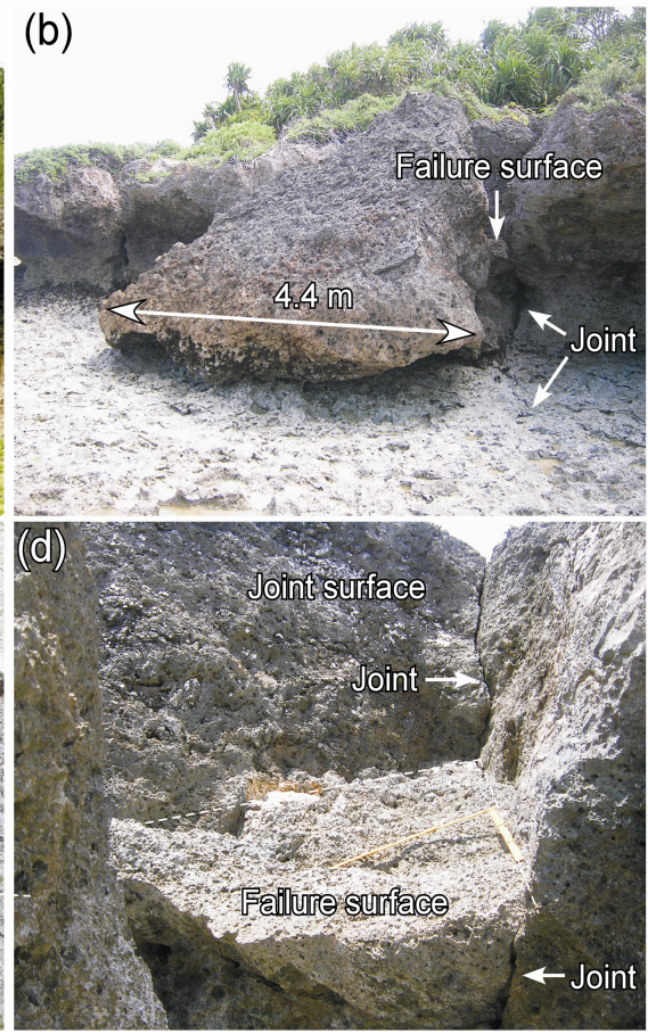

Figure 5. Cliff collapses around coastal cliffs (modified from Kogure \& Matsukura, 2010a). Fallen blocks with (a) quadrangular and (b) triangular flat surface. The pictures were taken at low tide. (c) Bird's-eye view of a fallen block with a quadrangular failure surface. The failure surface is bounded by a single vertical joint running parallel to the cliff face and two joints perpendicular to the face. (d) Cliff collapse scar with a triangular failure surface. The failure surface is bounded by two vertical joints.

Many fallen blocks have a quadrangular or triangular surface. In many cases, the cliffs behind the blocks have a matching failure surface. Kogure \& Matsukura (2010a) denoted collapses having a quadrangular or triangular failure surface as $\mathrm{H}_{\mathrm{q}}$-type or $\mathrm{H}_{\mathrm{t}}$-type collapse, respectively (Fig. 6). $\mathrm{H}_{\mathrm{q}}$-type collapse takes place at a cliff where three joints have intersected each other to form a quadrangular shape (Fig. 5a and 5c); two parallel joints develop perpendicular to a cliff face, and one joint runs almost parallel to the cliff face. Fig. 
$5 \mathrm{~b}$ and $5 \mathrm{~d}$ show a $\mathrm{H}_{\mathrm{t}}$-type collapse. Two vertical joints that were developing oblique to a cliff face intersected each other a few meters inland from the cliff face. The cliff bounded by the two vertical joints has collapsed at the horizontal surface (Fig. 5d). Cliff collapses in Kuroshima therefore display two shapes of failure surface, quadrangular and triangular, according to the number of joints and the angle between the joints and the cliff face. Blocks of both $\mathrm{H}_{\mathrm{q}}$ and $\mathrm{H}_{\mathrm{t}}$-type are distributed widely around the coasts of Kuro-shima. The distributions of $\mathrm{H}_{\mathrm{q}^{-}}$and $\mathrm{H}_{\mathrm{t}}$-type collapses appear to be controlled by the angle between the vertical joints and the cliff face (Kogure \& Matsukura, 2011).

\subsection{Tsunamis}

The most significant tectonic processes in the area of the Ryukyu Islands are the rifting of the Okinawa Trough and subduction of the Philippine Sea Plate. As a result of these processes the Ryukyu Arc is characterized by intense seismic and tectonic activity, leading to raised and faulted Pleistocene and Holocene coral reef tracts. Seismic activity often induces tsunamis. Coastal cliffs in the Ryukyu Islands have suffered damage from large tsunamis several times in history (e.g. Imamura, 1938; Kato \& Kimura, 1983; Nakata \& Kawana, 1995).
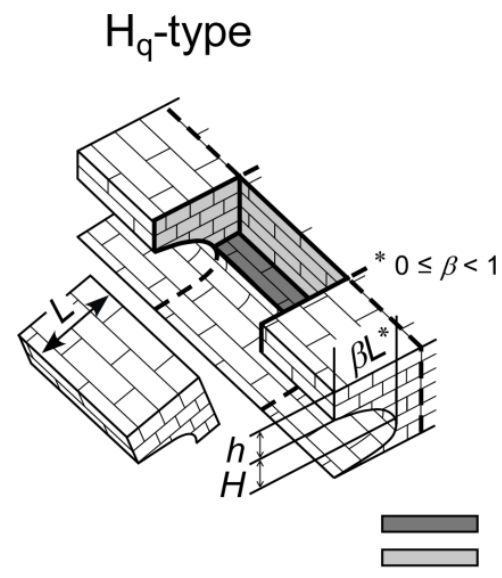

- - - Joint

\section{$\mathrm{H}_{\mathrm{t}}$-type}

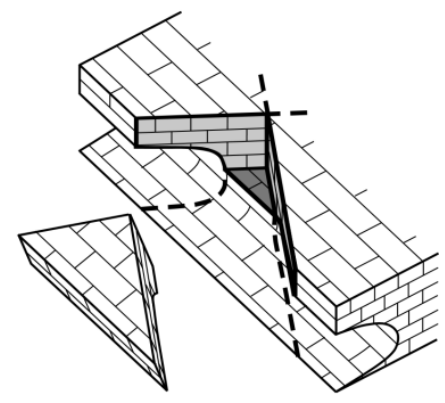

Failure surface

Joint surface

Figure 6. Schematic illustrations of $\mathrm{H}_{\mathrm{q}^{-}}$and $\mathrm{H}_{\mathrm{t}}$-type collapse (Kogure \& Matsukura, 2010b); $\beta$ denotes the ratio of notch depth to the block length, $L$. An $\mathrm{H}_{\mathrm{q}}$-type block derives from a cliff with a quadrangular failure surface, and an $\mathrm{H}_{\mathrm{t}}$-type block originates from a cliff with a triangular failure surface.

The largest tsunami on record is the 1771 Meiwa Tsunami caused by the Yaeyama Earthquake (M 7.4) on April 24, 1771. The maximum run-up height of the tsunami was estimated by Nakata \& Kawana (1995) to be more than $30 \mathrm{~m}$ on the south-eastern side of Ishigaki Island, and $5 \mathrm{~m}$ on the east and south side of Kuro-shima. Kato \& Matsuo (1998) have indicated the possibility of coastal cliff collapses due to historical tsunamis, especially 
the 1771 Meiwa Tsunami, in Kuro-shima. Nakata \& Kawana (1995) inferred the action of other large tsunamis prior to the Meiwa Tsunami, based on radiocarbon dating analysis. Many tsunami blocks that are composed of Holocene fossil corals are much older than the Meiwa period; in a few islands around Ishigaki Island, some are at much higher locations than the run-up height of the 1771 Meiwa Tsunami. According to Nakata \& Kawana (1995), such large tsunamis recur on timescale of hundreds or thousands of years in the southern Ryukyu Islands. They asserted that the southern Ryukyu Islands were inundated by large tsunamis about 600, 1000 and 2000 years before the present (yr BP); the tsunami at $2000 \mathrm{yr}$ $\mathrm{BP}$ was much higher than the Meiwa Tsunami.

The Ryukyu Islands are in a subtropical area, and in the summer and autumn they often experience typhoons. These give rise to bores that manifest as an extreme wave in the Ryukyu Islands. Severe damage to the coastal environment as a result of these bores has been reported from the late 1980s (e.g. Nakaza et al., 1988). Also in recent years, and especially in July 2007, extreme waves generated by a strong typhoon destroyed some social infrastructures in the southern part of Okinawa Island. Despite studies of the wave height and estimated wave pressure of extreme offshore waves during typhoons around the Ryukyu Islands, there is little information about these parameters for bores in coral reef lagoons which permits us to estimate the wave pressure. Below, we discuss the possibility of cliff collapses due to tsunamis.

\section{Methods}

\subsection{Stability analysis models}

According to Kogure \& Matsukura (2010b), wave-induced collapse proceeds as follows: (1) a developing notch forms a visor-like cantilever beam; (2) tensile stress is generated, from its own weight, on the horizontal plane that is level with the retreat point of the notch; (3) collapse occurs due to stress from wave impact, resulting in an 'upset' mode of collapse. The cantilever beam model (Timoshenko \& Gere, 1978, pp. 108-110) is suitable for estimating the critical notch depth. To obtain the critical failure stresses in $\mathrm{H}_{\mathrm{q}^{-}}$and $\mathrm{H}_{\mathrm{t}}$-type collapse, equations were derived based on this model.

Fig. 7 shows the relation between wave height, $H_{\mathrm{w}}$, and cliff height, $H^{*}$. When $H$ and $h$ are as shown in Fig. 6, and $H^{\prime}$ denotes the height from the reef flat to the retreat point of the cliff, $H^{*}$ is equal to the sum of $H^{\prime}, H$ and $h$. The relation can be divided into four cases (Kogure \& Matsukura, 2010b): (1) $H_{\mathrm{w}} \leq H^{\prime}$ (Case 1), in which that wave pressure does not operate on the notched roof; (2) $H^{\prime}<H_{\mathrm{w}} \leq H^{\prime}+H$ (Case 2), in which horizontal stress acts only on the notched roof; (3) $H^{\prime}+H<H_{\mathrm{w}} \leq H^{*}$ (Case 3), in which horizontal stress acts on the notched roof and part of the vertical cliff surface; and (4) $H^{*}<H_{\mathrm{w}}$ (Case 4), in which horizontal stress acts on the notched roof and the vertical cliff surface. In Case 1, waves have no effect on collapse because no stress acts on the notched roof. Stability analysis models are derived below for Cases 2, 3 and 4 . 
(a) Case 1: $H_{\mathrm{w}} \leq H^{\prime}$

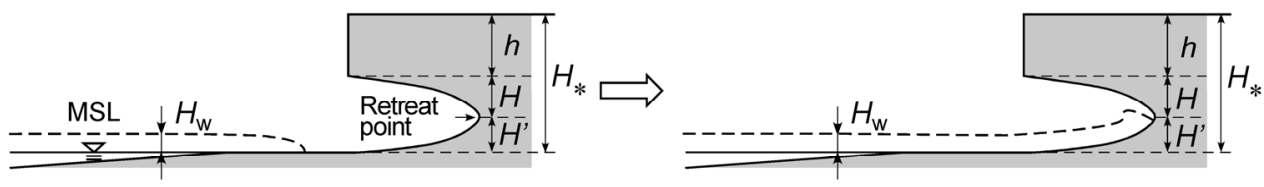

(b) Case 2: $H^{\prime}<H_{\mathrm{w}} \leq H^{\prime}+H$

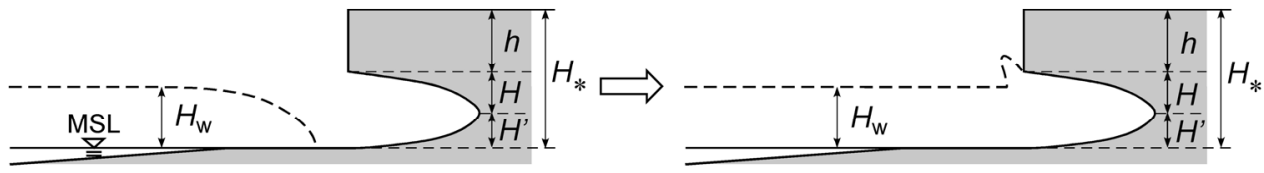

(c) Case 3: $H^{\prime}+H<H_{\mathrm{w}} \leq H_{*}$
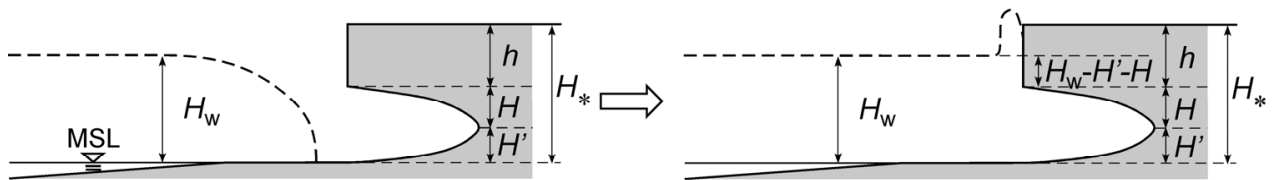

(d) Case 4: $H_{*}<H_{\mathrm{w}}$

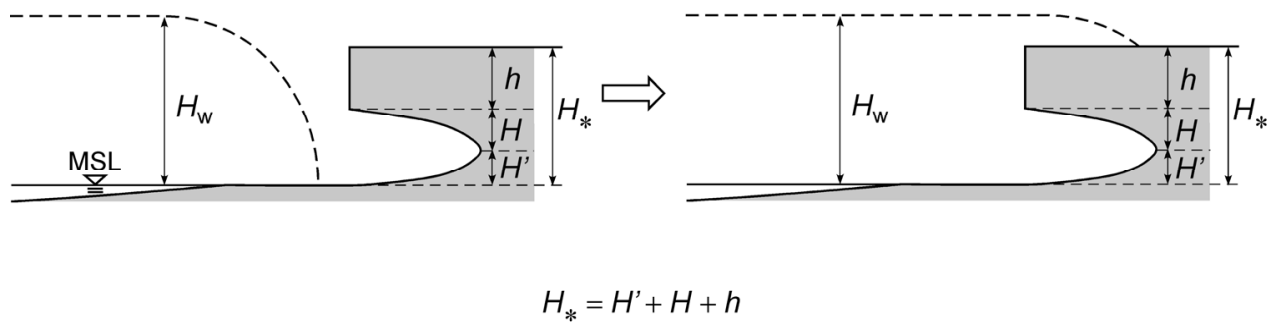

Figure 7. Relationships between wave height and cliff height used for calculating the stresses on a cliff (Kogure \& Matsukura, 2010b). Symbols denote: $H_{\mathrm{w}}$, wave height; $h$, cliff height corresponding to the vertical front face; $H$, cliff height corresponding to notched roof; $H^{\prime}$, height from reef flat to a retreat point of a notch; $H^{*}=H^{\prime}+H+h$.

Three forces are involved in cliff instability: (1) downward stress due to gravity, $\sigma \operatorname{tgmax},(2)$ upward stress due to waves, $\sigma_{\text {twmax }}$ and (3) the strength of the cliff material, i.e., the tensile strength, $S_{\text {t. }}$ The following equation gives the condition for wave-induced collapse:

$$
\sigma_{\text {twmax }} \geq \sigma_{\text {tgmax }}+S_{t}
$$

For a $\mathrm{H}_{\mathrm{q}}$-type cliff having a cliff height above the retreat point (referred to henceforth as the cliff height), $H+h$, the value of $\sigma$ tgmax operating on the retreat point of the notch (bold $\mathrm{E}$ in 
Fig. 8a) is shown as the sum of gravity-induced stress, $\sigma_{\mathrm{A}}$, and downward loading due to gravity, $\sigma$ в. (Both are shown in bold arrows in Fig. 8a.) This relation is

$$
\sigma_{\text {tgmax }}=\sigma_{\mathrm{A}}+\sigma_{\mathrm{B}}
$$

The values of $\sigma_{\mathrm{A}}$ and $\sigma_{\mathrm{B}}$ are:

$$
\begin{gathered}
\sigma_{\mathrm{A}}=\frac{\beta^{2} \rho g(H+3 h)}{(1-\beta)^{2}} \\
\sigma_{\mathrm{B}}=\rho g(H+h)
\end{gathered}
$$

where $\rho$ is the rock density and $g$ is the acceleration due to gravity. The value of $\sigma$ tgmax is given by substituting Eqs. (3) and (4) into Eq. (2), as:

$$
\sigma_{\text {tgmax }}=\frac{\beta^{2} \rho g(H+3 h)}{(1-\beta)^{2}}+\rho g(H+h)
$$

(a) $\mathrm{H}_{\mathrm{q}}$-type

Plan view

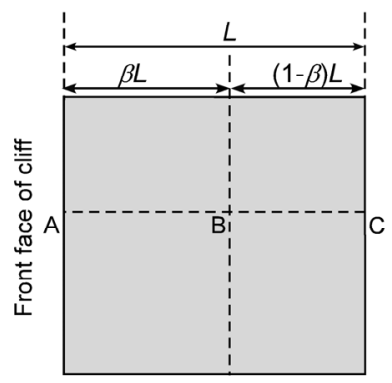

(b) $\mathrm{H}_{\mathrm{t}}$-type

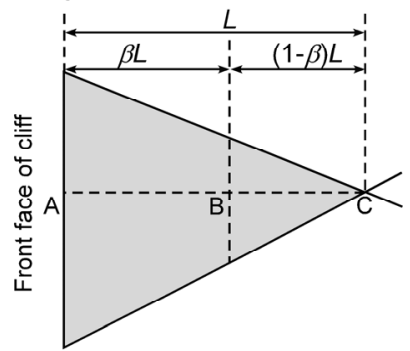

Stress distribution for $\sigma_{\text {tgmax }}$

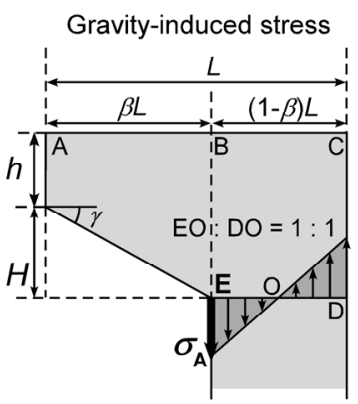

Downward loading due to gravity
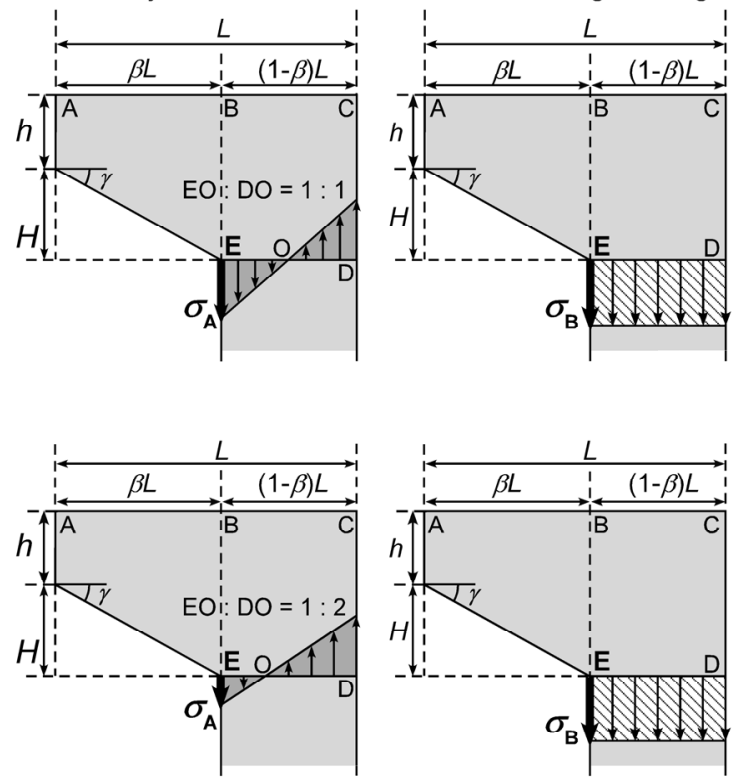

Figure 8. Notation for the dimensions of cliffs and the distribution of gravity-induced stress inside a cliff (Kogure \& Matsukura, 2010b). (a) Hq-type, (b) Ht-type. 
Wave pressure acts on a notched roof when waves fill up a notch; a cliff experiences both vertical and horizontal components of wave pressure through the whole of the notched roof (Fig. 9). Cliffs are also subject to buoyancy according to the underwater volumes of the cliffs. For a $\mathrm{H}_{\mathrm{q}}$-type cliff, in Case 2 (Fig. $7 \mathrm{~b}$ ), having cliff height $H+h$, with distance $L$ between the cliff face and a vertical joint parallel to the cliff face, notch depth $\beta L(0 \leq \beta<1)$ and angle $\gamma$, the maximum value of $\sigma$ twmax at $\mathrm{E}$ in Fig. 9a is given by:

$$
\sigma_{\mathrm{tw} \max }=\frac{3 \beta^{2} P \cos \gamma}{(1-\beta)^{2}}+\frac{3 H^{2} P \sin \gamma}{(1-\beta)^{2} L^{2}}+\frac{\beta^{2} \rho_{\mathrm{sw}} g H}{(1-\beta)^{2}}
$$

where $P$ is the wave pressure and $\rho_{\mathrm{sw}}$ is the density of sea water. In Cases 3 and 4 , the value of $\sigma$ twmax is given respectively by:

$$
\begin{gathered}
\sigma_{\mathrm{tw} \max }=\frac{3 \beta^{2} P \cos \gamma}{(1-\beta)^{2}}+\frac{3 H^{2} P \sin \gamma}{(1-\beta)^{2} L^{2}}+\frac{3 P\left(H_{\mathrm{w}}-H^{\prime}-H\right)^{2}}{(1-\beta)^{2} L^{2}}+\frac{4 \beta^{2} \rho_{\mathrm{sw}} g\left(2 H_{\mathrm{w}}-H^{\prime}-H\right)(H+3 h)}{(1-\beta)^{2}(H+2 h)} \\
\sigma_{\mathrm{tw} \max }=\frac{3 H^{2} P \sin \gamma}{(1-\beta)^{2} L^{2}}+\frac{3 h P(2 H+h)}{(1-\beta)^{2} L^{2}}+\frac{3 \beta^{2} P \cos \gamma}{(1-\beta)^{2}}+\frac{\beta^{2} \rho_{\mathrm{sw}} g(H+3 h)}{(1-\beta)^{2}}
\end{gathered}
$$

(a) $\mathrm{H}_{\mathrm{q}}$-type

\section{Plan view of the cliff}

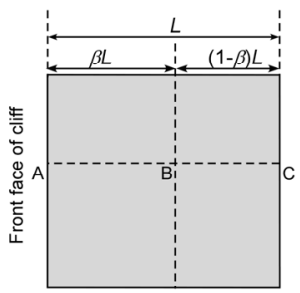

(b) $\mathrm{H}_{\mathrm{t}}$-type

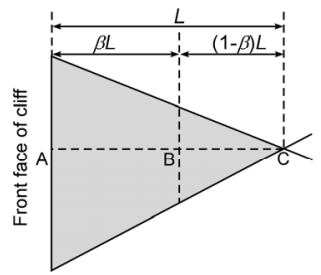

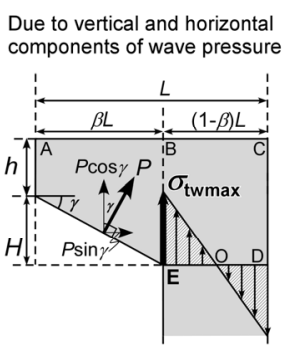

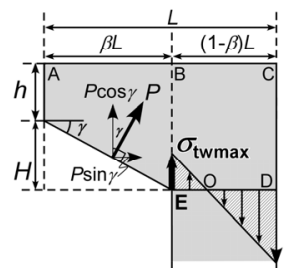

Stress distribution for $\sigma_{\mathrm{twmax}}$

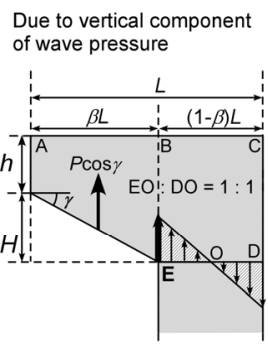

Due to horizontal component of wave pressure
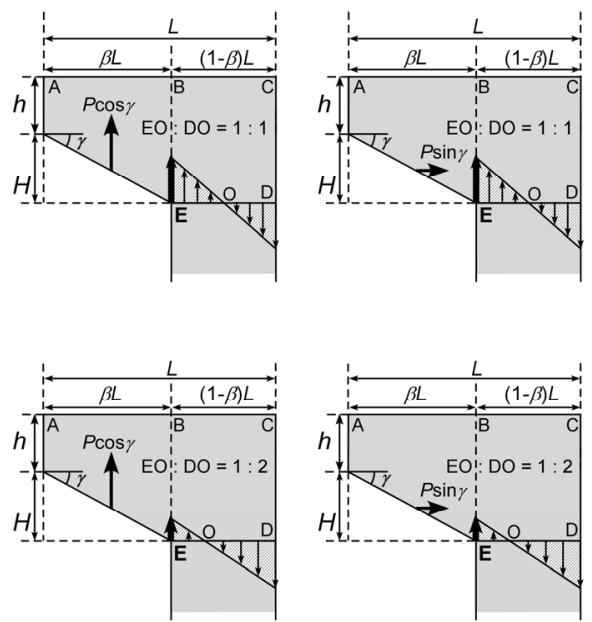

Figure 9. Distribution of wave-induced stresses inside a cliff (Kogure \& Matsukura, 2010b). (a) $\mathrm{H}_{\mathrm{q}}$-type, (b) $\mathrm{H}_{\mathrm{t}}$-type. Relative lengths of arrows do not correspond to the values of stresses. 
For a Ht-type cliff (Figs. $8 \mathrm{~b}$ and $9 \mathrm{~b}$ ), the values of $\sigma_{\text {tgmax }}$ and $\sigma_{\text {twmax }}$ can be obtained as above for a $\mathrm{H}_{\mathrm{q}}$-type cliff. The equations obtained for a $\mathrm{H}_{\mathrm{t}}$-type cliff are set out in Table 1, numbered from Eq. (9) to (12).

\begin{tabular}{cc}
\hline Hq-type Ht-type \\
\hline$\sigma$ ax
\end{tabular}

$\sigma \operatorname{tgmax}$

Equation (5):

$\frac{\beta^{2} \rho g(H+3 h)}{(1-\beta)^{2}}+\rho g(H+h)$
Equation (9):

$$
\begin{aligned}
& \frac{\beta^{2} \rho g}{(1-\beta)^{3}}\{2(H+3 h)-\beta(H+2 h)\} \\
& +\rho g(H+h)
\end{aligned}
$$

$\sigma$ twmax

Case 2

Equation (6):

$$
\frac{3 \beta^{2} P \cos \gamma}{(1-\beta)^{2}}+\frac{3 H^{2} P \sin \gamma}{(1-\beta)^{2} L^{2}}+\frac{\beta^{2} \rho_{\mathrm{sw}} g H}{(1-\beta)^{2}}
$$

Equation (10):

$$
\begin{aligned}
& \frac{2 \beta^{2}(3-\beta) P \cos \gamma}{(1-\beta)^{3}}+\frac{2(3-\beta) H^{2} P \sin \gamma}{(1-\beta)^{3} L^{2}} \\
& +\frac{\beta^{2}(2-\beta) \rho_{\mathrm{sw}} g H}{(1-\beta)^{3}}
\end{aligned}
$$

Case 3

Equation (7):

$$
\text { Equation (11): }
$$

$$
\begin{aligned}
& \frac{3 \beta^{2} P \cos \gamma}{(1-\beta)^{2}}+\frac{3 H^{2} P \sin \gamma}{(1-\beta)^{2} L^{2}}+\frac{3 P\left(H_{\mathrm{w}}-H^{\prime}-H\right)^{2}}{(1-\beta)^{2} L^{2}} \\
& +\frac{4 \beta^{2} \rho_{\mathrm{sw}} g\left(2 H_{\mathrm{w}}-2 H^{\prime}-H\right)(H+3 h)}{(1-\beta)^{2}(H+2 h)}
\end{aligned}
$$

$$
\begin{aligned}
& \frac{2 \beta^{2}(3-\beta) P \cos \gamma}{(1-\beta)^{3}}+\frac{2(3-\beta) H^{2} P \sin \gamma}{(1-\beta)^{3} L^{2}} \\
& +\frac{6 P\left(H_{\mathrm{w}}-H^{\prime}-H\right)^{2}}{(1-\beta)^{3} L^{2}} \\
& +\frac{\beta^{2} \rho_{\mathrm{sw}} g}{(1-\beta)^{3}}\left\{(2-\beta) H+2(3-\beta)\left(H_{\mathrm{w}}-H^{\prime}-H\right)\right\}
\end{aligned}
$$

Case 4

Equation (8):

$$
\begin{aligned}
& \frac{2(3-\beta) H^{2} P \sin \gamma}{(1-\beta)^{3} L^{2}}+\frac{6 h P(2 H+h)}{(1-\beta)^{3} L^{2}} \\
& +\frac{2 \beta^{2}(3-\beta) P \cos \gamma}{(1-\beta)^{3}} \\
& +\frac{\beta^{2} \rho_{\mathrm{Sw}} g}{(1-\beta)^{3}}\{(2-\beta) H+2(3-\beta) h\}
\end{aligned}
$$

Table 1. Equations for estimating the value of $\sigma_{\text {tgmax }}$ and $\sigma_{\text {twmax }}$ for stability analysis (Kogure \& Matsukura, 2010b). 


\subsection{Parameters for stability analysis}

The stability analysis requires information on the dimensions of cliffs and blocks, $H^{\prime}, H, h, L$, $\beta L$ and $\gamma$, the physical and mechanical properties $S_{\mathrm{t}}$ and $\rho$ of the cliff material, i.e. Ryukyu limestone, and the wave pressure, $P$. These parameters are characterized as follows.

\subsubsection{Dimensions of blocks and cliffs and rock properties of Ryukyu limestone}

Of the blocks scattered around the coastal cliff, blocks of clearly identifiable type with identifiable place of origin on the cliff face were chosen for the present analysis. In addition to the blocks, the dimensions of two cliffs identified as Ht-type, including that in Fig. 4b, were measured by a laser finder and a measuring stick. Table 2 shows the data for the heights $(H$ and $h)$ and lengths $(L)$ of the blocks and cliffs. The values of $H, h, L$ and $\beta L$ are 0.9 $1.5 \mathrm{~m}, 0-1.7 \mathrm{~m}, 2.0-7.0 \mathrm{~m}$, and $0.7-4.8 \mathrm{~m}$ for H -type blocks, $1.3-1.5 \mathrm{~m}, 0-1.7 \mathrm{~m}, 2.4-6.1 \mathrm{~m}$ and 0.9-3.6 m for Ht-type blocks, and $1.4 \mathrm{~m}, 0 \mathrm{~m}, 3.4-4.7 \mathrm{~m}$ and 2.0-2.7 m for Ht-type cliffs.

Kogure \& Matsukura (2010b) measured the values of $\gamma$ and $H^{\prime}$. The value of $\gamma$ is $20^{\circ}$ for every block, and the value of $H^{\prime}$ is the same for every cliff in Kuro-shima, i.e. $1.5 \mathrm{~m}$. The value of $S_{\mathrm{t}}$ for Ryukyu limestone can be estimated using the scaling equation proposed by Kogure et al. (2006); $S_{\mathrm{t}}$ is given in terms of the length of the horizontal failure surface, $(1-\beta) L$, as:

$$
S_{\mathrm{t}}=1000\left[5.6\{100(1-\beta) L\}^{-0.6}+0.6\right]
$$

where the units of $S_{\mathrm{t}}$ and $L$ are $\mathrm{kPa}$ and meters. The physical properties of Ryukyu limestone in Kuro-shima have been given by Kogure \& Matsukura (2010a), and $\rho=2.35 \mathrm{Mg} / \mathrm{m}^{3}$.

\begin{tabular}{|c|c|c|c|c|c|}
\hline \multirow[b]{2}{*}{ No. } & \multicolumn{3}{|c|}{ Height } & \multirow{2}{*}{$\begin{array}{c}\text { Length } \\
L(\mathrm{~m})\end{array}$} & \multirow{2}{*}{$\frac{\text { Notch depth }}{\beta L(\mathrm{~m})}$} \\
\hline & $H(\mathrm{~m})$ & $h(\mathrm{~m})$ & $H+h(\mathrm{~m})$ & & \\
\hline $\mathrm{H}_{\mathrm{q}-1}$ & 1.5 & 1.1 & 2.6 & 7.0 & 4.8 \\
\hline $\mathrm{H}_{\mathrm{q}}-2$ & 1.5 & 0.5 & 2.0 & 3.4 & 2.3 \\
\hline $\mathrm{H}_{\mathrm{q}-3}$ & 1.5 & 1.5 & 3.0 & 5.0 & 3.6 \\
\hline $\mathrm{H}_{\mathrm{q}}-4$ & 1.5 & 0.4 & 1.9 & 2.8 & 2.2 \\
\hline $\mathrm{H}_{\mathrm{q}}-5$ & 1.5 & 1.5 & 3.0 & 3.0 & 2.4 \\
\hline $\mathrm{H}_{\mathrm{q}}-6$ & 1.5 & 1.2 & 2.7 & 3.8 & 3.2 \\
\hline $\mathrm{H}_{\mathrm{q}-7}$ & 1.0 & 0 & 1.0 & 3.6 & 2.0 \\
\hline $\mathrm{H}_{\mathrm{q}}-8$ & 1.5 & 0.3 & 1.8 & 4.6 & 2.2 \\
\hline $\mathrm{H}_{\mathrm{q}-9}$ & 1.2 & 0 & 1.2 & 2.3 & 1.9 \\
\hline $\mathrm{H}_{\mathrm{q}}-10$ & 1.5 & 0.7 & 2.2 & 3.9 & 2.0 \\
\hline $\mathrm{H}_{\mathrm{q}}-11$ & 1.5 & 1.0 & 2.5 & 3.2 & 1.4 \\
\hline $\mathrm{H}_{\mathrm{q}}-12$ & 1.5 & 0.1 & 1.6 & 5.4 & 3.5 \\
\hline $\mathrm{H}_{\mathrm{q}}-13$ & 1.0 & 0 & 1.0 & 3.5 & 0.7 \\
\hline $\mathrm{H}_{\mathrm{q}}-14$ & 1.5 & 0.8 & 2.3 & 6.8 & 3.6 \\
\hline $\mathrm{H}_{\mathrm{q}}-15$ & 1.5 & 0.2 & 1.7 & 2.5 & 2.1 \\
\hline
\end{tabular}


Tsunami - Analysis of a Hazard - From Physical Interpretation to Human Impact

\begin{tabular}{|c|c|c|c|c|c|}
\hline $\mathrm{H}_{\mathrm{q}}-16$ & 1.5 & 1.1 & 2.6 & 3.6 & 2.7 \\
\hline $\mathrm{H}_{\mathrm{q}}-17$ & 1.5 & 0.9 & 2.4 & 4.2 & 2.7 \\
\hline $\mathrm{H}_{\mathrm{q}}-18$ & 1.5 & 0.3 & 1.8 & 5.0 & 3.9 \\
\hline $\mathrm{H}_{\mathrm{q}}-19$ & 1.5 & 0.9 & 2.4 & 3.2 & 2.6 \\
\hline $\mathrm{H}_{\mathrm{q}}-20$ & 1.5 & 0.6 & 2.1 & 2.5 & 1.9 \\
\hline $\mathrm{H}_{\mathrm{q}}-21$ & 1.5 & 0.9 & 2.4 & 3.6 & 3.0 \\
\hline $\mathrm{H}_{\mathrm{q}}-22$ & 1.5 & 1.1 & 2.6 & 2.5 & 1.9 \\
\hline $\mathrm{H}_{\mathrm{q}}-23$ & 1.5 & 0.8 & 2.3 & 3.9 & 2.5 \\
\hline $\mathrm{H}_{\mathrm{q}}-24$ & 1.5 & 1.0 & 2.5 & 3.7 & 3.1 \\
\hline $\mathrm{H}_{\mathrm{q}}-25$ & 1.4 & 0 & 1.4 & 2.0 & 1.6 \\
\hline $\mathrm{H}_{\mathrm{q}}-26$ & 1.4 & 0 & 1.4 & 2.6 & 1.5 \\
\hline $\mathrm{H}_{\mathrm{q}}-27$ & 0.9 & 0 & 0.9 & 3.7 & 3.1 \\
\hline $\mathrm{H}_{\mathrm{q}}-28$ & 1.0 & 0 & 1.0 & 4.0 & 2.0 \\
\hline $\mathrm{H}_{\mathrm{q}}-29$ & 1.2 & 0 & 1.2 & 2.5 & 1.4 \\
\hline $\mathrm{H}_{\mathrm{q}}-30$ & 1.5 & 0.5 & 2.0 & 4.4 & 3.6 \\
\hline $\mathrm{H}_{\mathrm{q}}-31$ & 1.5 & 1.7 & 3.2 & 3.4 & 2.6 \\
\hline $\mathrm{H}_{\mathrm{q}}-32$ & 1.3 & 0 & 1.3 & 2.0 & 1.3 \\
\hline $\mathrm{H}_{\mathrm{q}}-33$ & 1.5 & 0.4 & 1.9 & 3.9 & 2.9 \\
\hline $\mathrm{H}_{\mathrm{q}}-34$ & 1.5 & 0.3 & 1.8 & 4.1 & 2.0 \\
\hline $\mathrm{H}_{\mathrm{q}}-35$ & 1.3 & 0 & 1.3 & 2.2 & 1.6 \\
\hline $\mathrm{H}_{\mathrm{t}}-1$ & 1.5 & 0.8 & 2.3 & 3.8 & 2.1 \\
\hline $\mathrm{H}_{\mathrm{t}}-2$ & 1.5 & 0.5 & 2.0 & 2.6 & 0.9 \\
\hline $\mathrm{H}_{\mathrm{t}}-3$ & 1.5 & 0 & 1.5 & 3.3 & 1.9 \\
\hline $\mathrm{H}_{\mathrm{t}}-4$ & 1.4 & 0 & 1.4 & 2.4 & 1.4 \\
\hline $\mathrm{H}_{\mathrm{t}-5}$ & 1.5 & 0.8 & 2.3 & 5.0 & 3.2 \\
\hline $\mathrm{H}_{\mathrm{t}}-6$ & 1.5 & 0.8 & 2.3 & 4.7 & 2.2 \\
\hline $\mathrm{H}_{\mathrm{t}}-7$ & 1.5 & 0.7 & 2.2 & 3.1 & 1.7 \\
\hline $\mathrm{H}_{\mathrm{t}}-8$ & 1.5 & 1.7 & 3.2 & 6.1 & 3.6 \\
\hline $\mathrm{H}_{\mathrm{t}}-9$ & 1.5 & 0.9 & 2.4 & 5.1 & 3.1 \\
\hline $\mathrm{H}_{\mathrm{t}}-10$ & 1.5 & 0.5 & 2.0 & 4.3 & 2.6 \\
\hline $\mathrm{H}_{\mathrm{t}}-11$ & 1.5 & 0.9 & 2.4 & 2.7 & 1.5 \\
\hline $\mathrm{H}_{\mathrm{t}}-12$ & 1.5 & 0.6 & 2.1 & 2.8 & 1.8 \\
\hline $\mathrm{H}_{\mathrm{t}}-13$ & 1.5 & 0.5 & 2.0 & 4.5 & 2.8 \\
\hline $\mathrm{H}_{\mathrm{t}}-14$ & 1.3 & 0 & 1.3 & 3.3 & 2.1 \\
\hline $\mathrm{H}_{\mathrm{t}}-15$ & 1.5 & 0.2 & 1.7 & 3.3 & 1.9 \\
\hline $\mathrm{H}_{\mathrm{t}}-16$ & 1.5 & 0.8 & 2.3 & 3.4 & 1.8 \\
\hline $\mathrm{H}_{\mathrm{t}}-17$ & 1.3 & 0 & 1.3 & 3.4 & 1.0 \\
\hline $\mathrm{H}_{\mathrm{t}}-18$ & 1.5 & 0.6 & 2.1 & 3.7 & 1.9 \\
\hline $\mathrm{H}_{\mathrm{t}-19}$ & 1.4 & 0 & 1.4 & 2.8 & 1.5 \\
\hline $\mathrm{H}_{\mathrm{t}}-\mathrm{C}^{*}$ & 1.4 & 0 & 1.5 & 3.4 & 2.0 \\
\hline $\mathrm{H}_{\mathrm{t}}-\mathrm{C}^{*}$ & 1.4 & 0 & 1.5 & 4.7 & 2.7 \\
\hline
\end{tabular}

Table 2. Results of measurements of blocks (Kogure \& Matsukura, 2010b) and cliffs. 


\subsubsection{Estimation of wave pressure}

The dynamic pressure of waves at a cliff, $P$, used in Eqs.6-8 and 10-12 (Table 1), is given as a simple product of parameters such as $\rho_{\mathrm{sw}}, g$, and wave height, $H_{\mathrm{w}}$ (e.g. Hom-maand Horikawa, 1964) as:

$$
P=k \rho_{\mathrm{sw}} g H_{\mathrm{w}}
$$

where $k$ is termed the coefficient of wave pressure. Eq.14 provides the maximum dynamic pressure exerted on a vertical seawall in the horizontal direction, derived from experimental data. Use of Eq. 14 in this study should take into account the shape of the target object (vertical seawall and notched cliff) and the direction of wave pressure (horizontal and obliquely upward). In spite of detailed research into coastal engineering, no equations have been derived for the wave pressure in the present situation. Extreme waves compacted into a notch are believed to generate the same pressure in all directions, because the water conforms to Pascal's principle during such extreme events. If a significant notch developed on the cliff, it would experience high pressure on its face. We therefore use Eq. 14 to calculate the wave pressure under the assumption that large waves filling up the entire notch exert the same pressure on the notched face perpendicularly and in the horizontal direction.

Some studies have been made of the value of $k$ for tsunamis. Ikeno et al. (1998) considered the $k$-value of a tsunami in which the wave crest is divided into two or more parts in propagation at a shallow beach, and the crests collapse just before reaching a coast having cliffs and breakwaters. This type of tsunami causes severe damage to the coastal environment. Ikeno et al. (1998) proposed a $k$-value of 3.5, and Kogure \& Matsukura (2010b) used this value. We do the same.

\section{Results and discussion}

\subsection{Calculation of critical wave height}

To determine the effect of wave impact on the cliffs, we perform a stability analysis for the blocks and the cliffs listed in Table 2. The critical condition for wave-induced collapse is equality of the left- and right-hand side of Eq. 1. The right-hand side is given by Eqs. 5 and 13 for $\mathrm{H}_{\mathrm{q}}$-type, and by Eqs. 9 and 13 for $\mathrm{H}_{\mathrm{t}}$-type:

$$
\begin{aligned}
\sigma_{\text {tgmax }}+S_{\mathrm{t}}=\frac{\beta^{2} \rho g(H+3 h)}{(1-\beta)^{2}}+\rho g(H+h)+1000\left[5.6\{100(1-\beta) L\}^{-0.6}+0.6\right] \\
\sigma_{\text {tgmax }}+S_{\mathrm{t}}=\frac{\beta^{2} \rho g}{(1-\beta)^{3}}\{2(H+3 h)-\beta(H+2 h)\}+\rho g(H+h)+ \\
+1000\left[5.6\{100(1-\beta) L\}^{-0.6}+0.6\right]
\end{aligned}
$$


To estimate the wave pressure in Eq. 14, Kogure \& Matsukura (2010b) took $k=3.5$ and $\rho_{\mathrm{sw}}=$ $1.02 \mathrm{Mg} / \mathrm{m}^{3}$; this is the density of sea water at $26.3{ }^{\circ} \mathrm{C}$, which was the annual sea surface temperature observed in 1998 by Ishigaki-jima Local Meteorological Observatory. Also, $g=$ $9.81 \mathrm{~m} / \mathrm{s}^{2}$.

\begin{tabular}{|c|c|c|c|c|c|c|c|}
\hline No. & $H^{*}(\mathrm{~m})$ & $H_{\mathrm{wc}}(\mathrm{m})$ & Case & No. & $H^{*}(\mathrm{~m})$ & $H_{\mathrm{wc}}(\mathrm{m})$ & Case \\
\hline $\mathrm{H}_{\mathrm{q}-1}$ & 4.1 & 2.8 & 2 & $\mathrm{H}_{\mathrm{q}-29}$ & 2.7 & 4.9 & 4 \\
\hline $\mathrm{H}_{\mathrm{q}}-2$ & 3.5 & 2.4 & 2 & $\mathrm{H}_{\mathrm{q}}-30$ & 3.5 & 1.0 & 1 \\
\hline $\mathrm{H}_{\mathrm{q}}-3$ & 4.5 & 2.6 & 2 & $\mathrm{H}_{\mathrm{q}-31}$ & 4.7 & 2.2 & 2 \\
\hline $\mathrm{H}_{\mathrm{q}}-4$ & 3.4 & 1.1 & 1 & $\mathrm{H}_{\mathrm{q}-32}$ & 2.8 & 2.4 & 2 \\
\hline $\mathrm{H}_{\mathrm{q}}-5$ & 4.5 & 1.7 & 2 & $\mathrm{H}_{\mathrm{q}-33}$ & 3.4 & 1.5 & 1 \\
\hline $\mathrm{H}_{\mathrm{q}}-6$ & 4.2 & 1.3 & 1 & $\mathrm{H}_{\mathrm{q}-34}$ & 3.3 & 6.8 & 4 \\
\hline $\mathrm{H}_{\mathrm{q}}-7$ & 2.5 & 5.4 & 4 & $\mathrm{H}_{\mathrm{q}-35}$ & 2.8 & 1.4 & 1 \\
\hline $\mathrm{H}_{\mathrm{q}}-8$ & 3.3 & 7.6 & 4 & $\mathrm{H}_{\mathrm{t}-1}$ & 3.8 & 2.1 & 2 \\
\hline $\mathrm{H}_{\mathrm{q}-9}$ & 2.7 & 0.6 & 1 & $\mathrm{H}_{\mathrm{t}-2}$ & 3.5 & 3.6 & 4 \\
\hline $\mathrm{H}_{\mathrm{q}}-10$ & 3.7 & 4.6 & 4 & $\mathrm{H}_{\mathrm{t}-3}$ & 3.0 & 1.3 & 1 \\
\hline $\mathrm{H}_{\mathrm{q}-11}$ & 4.0 & 4.4 & 4 & $\mathrm{H}_{\mathrm{t}}-4$ & 2.9 & 1.2 & 1 \\
\hline $\mathrm{H}_{\mathrm{q}-12}$ & 3.1 & 2.7 & 2 & $\mathrm{H}_{\mathrm{t}-5}$ & 3.8 & 1.4 & 1 \\
\hline $\mathrm{H}_{\mathrm{q}-13}$ & 2.5 & 76.0 & 4 & $\mathrm{H}_{\mathrm{t}}-6$ & 3.8 & 3.4 & 3 \\
\hline $\mathrm{H}_{\mathrm{q}-14}$ & 3.8 & 5.5 & 4 & $\mathrm{H}_{\mathrm{t}}-7$ & 3.7 & 2.0 & 2 \\
\hline $\mathrm{H}_{\mathrm{q}-15}$ & 3.2 & 0.7 & 1 & $\mathrm{H}_{\mathrm{t}}-8$ & 4.7 & 2.4 & 2 \\
\hline $\mathrm{H}_{\mathrm{q}}-16$ & 4.1 & 1.9 & 2 & $\mathrm{H}_{\mathrm{t}}-9$ & 3.9 & 1.7 & 2 \\
\hline $\mathrm{H}_{\mathrm{q}}-17$ & 3.9 & 2.8 & 2 & $\mathrm{H}_{\mathrm{t}}-10$ & 3.5 & 1.5 & 1 \\
\hline $\mathrm{H}_{\mathrm{q}}-18$ & 3.3 & 1.1 & 1 & $\mathrm{H}_{\mathrm{t}-11}$ & 3.9 & 2.0 & 2 \\
\hline $\mathrm{H}_{\mathrm{q}}-19$ & 3.9 & 1.3 & 1 & $\mathrm{H}_{\mathrm{t}-12}$ & 3.6 & 1.1 & 1 \\
\hline $\mathrm{H}_{\mathrm{q}}-20$ & 3.6 & 1.4 & 1 & $\mathrm{H}_{\mathrm{t}-13}$ & 3.5 & 1.3 & 1 \\
\hline $\mathrm{H}_{\mathrm{q}}-21$ & 3.9 & 1.2 & 1 & $\mathrm{H}_{\mathrm{t}-14}$ & 2.8 & 0.9 & 1 \\
\hline $\mathrm{H}_{\mathrm{q}}-22$ & 4.1 & 1.7 & 2 & $\mathrm{H}_{\mathrm{t}-15}$ & 3.2 & 1.5 & 1 \\
\hline $\mathrm{H}_{\mathrm{q}}-23$ & 3.8 & 2.6 & 2 & $\mathrm{H}_{\mathrm{t}-16}$ & 3.8 & 2.4 & 2 \\
\hline $\mathrm{H}_{\mathrm{q}-24}$ & 4.0 & 1.2 & 1 & $\mathrm{H}_{\mathrm{t}-17}$ & 2.8 & 12.0 & 4 \\
\hline $\mathrm{H}_{\mathrm{q}}-25$ & 2.9 & 0.8 & 1 & $\mathrm{H}_{\mathrm{t}}-18$ & 3.6 & 2.6 & 2 \\
\hline $\mathrm{H}_{\mathrm{q}}-26$ & 2.9 & 4.2 & 4 & $\mathrm{H}_{\mathrm{t}-19}$ & 2.9 & 1.8 & 2 \\
\hline $\mathrm{H}_{\mathrm{q}}-27$ & 2.4 & 0.5 & 1 & $\mathrm{H}_{\mathrm{t}}-\mathrm{C} 1^{*}$ & 4.2 & 2.0 & 2 \\
\hline $\mathrm{H}_{\mathrm{q}}-28$ & 2.5 & 8.1 & 4 & $\mathrm{H}_{\mathrm{t}}-\mathrm{C} 2^{*}$ & 4.1 & 2.2 & 2 \\
\hline
\end{tabular}

*Cliff

Table 3. Critical wave heights for collapses.

Kogure \& Matsukura (2010b) calculated the critical wave height $H_{\mathrm{wc}}$ at which wave-induced collapse occurs, as follows: (1) the value of $\sigma_{\operatorname{tgmax}}+S_{\mathrm{t}}$ was calculated by substituting the data for each block and cliff into Eq. 15 for $\mathrm{H}_{\mathrm{q}}$-type, or Eq. 16 for Ht-type; (2) Eq. 14 giving the wave pressure was substituted into Eqs. 6 or 7 or 8 ( $\mathrm{H}_{\mathrm{q}}$-type), or Eqs. 10 or 11 or 12 (Ht-type), to calculate the value of $\sigma_{\text {twmax }}$ (3) once the data for each block and cliff except $H_{\mathrm{w}}$ had been substituted into those equations, $H_{\mathrm{wc}}$ was determined as the critical wave height, so that the 
value of $\sigma_{\mathrm{twmax}}$ matched $\sigma_{\mathrm{tgmax}}+S_{\mathrm{t}}$. The value of $H_{\mathrm{wc}}$ shows the minimum wave height required to induce collapse for each block-and-cliff combination. Table 3 shows the calculated values of $H_{w c}$, with reference to the relationship between wave height and cliff height (Fig. 7). The resulting values of $H_{\mathrm{wc}}$ are $0.5-76.0 \mathrm{~m}$. Kogure \& Matsukura (2010b) argued that $H_{\mathrm{wc}}=76.0 \mathrm{~m}$ for $\mathrm{H}_{\mathrm{q}}-13$ is not a realistic value, and the analysis therefore excludes $\mathrm{H}_{\mathrm{q}}-13$.

\subsection{Distribution of wave-provided blocks}

To distinguish between blocks produced by gravitational or wave-induced collapse, the blocks and the cliffs were classified into Cases 1-4 in Fig. 7 according to the relationship between $H^{*}$ and $H_{\mathrm{wc}}$ (Table 3 ). Blocks classified as Case 1 appear to have been produced by gravitational collapse, because the waves cannot reach a notched roof in this case (Fig. 7a). Blocks classified into Cases 2-4 may involve collapse due to waves (Fig. 7b, 7c and 7d). Especially, blocks classified as Case 4 derive from wave-induced collapse. The cliffs $\mathrm{H}_{\mathrm{t}} \mathrm{C} 1$ and $\mathrm{C} 2$ were classified as Case 2.

The blocks broken off by tsunamis were plotted on an air photograph of Kuro-shima, together with blocks fallen due to gravity (Fig. 10). The tsunami-induced blocks are concentrated in the south-eastern and south-western coasts, whereas the gravity-caused blocks are distributed evenly along the coastlines.

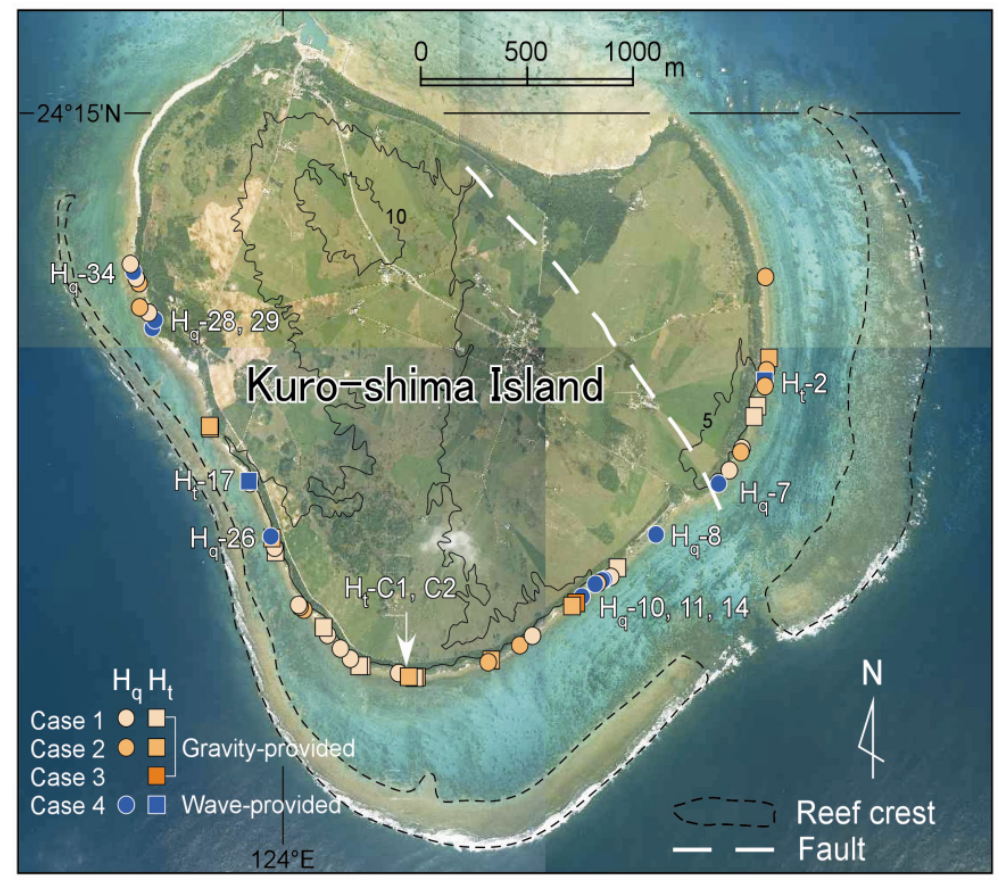

Figure 10. Comparison of distributions between blocks and fringing reefs around Kuro-shima Island. The names of blocks classified as Case 4 are shown on this figure in addition to those of $\mathrm{H}_{\mathrm{t}} \mathrm{C} 1$ and $\mathrm{C} 2$. 
The distance from the coast to the offshore reef edge is about $800 \mathrm{~m}$ in the south-eastern area, the farthest offshore in Kuro-shima and indicating that the fringing reefs are highly developed. These fringing reefs are cut by a fault running NW-SE which makes them discontinuous. Tsunamis must therefore have invaded the south-eastern coastal area through this gap, giving rise to the cliff collapses. In the south-western area, the distance between the coastline and reef edge is about $200 \mathrm{~m}$, the smallest value in Kuro-shima. Additionally, the reef crest is poorly developed and its width is the narrowest in the island. Reduction of the height of tsunamis by these fringing reefs must have been inadequate to prevent the collapses.

\subsection{Effects of fringing reefs in reducing the height of tsunamis}

Fig. 10 indicates that there are two factors affecting the height of tsunamis invading these coasts. One factor is the distance between the coastlines and reef edge; the other is continuity of the fringing reefs and their development.

Comparison of the distribution of the blocks between the southern and south-western areas clearly shows the effect of distance from the coastlines to the reef edge. For all blocks classified as Case $4\left(\mathrm{H}_{\mathrm{q}}-7,8,10,11,14,26,28,29,34, \mathrm{H}_{\mathrm{t}}-2\right.$ and 17), the average value of $H_{\mathrm{wc}}$ is $6.6 \mathrm{~m}$. It follows that tsunamis having height approximately $6.6 \mathrm{~m}$ must have attacked the south-eastern and south-western coasts, causing collapse of the cliffs. In contrast, the average value of $H_{\mathrm{wc}}$ is 2.1 $\mathrm{m}$ for the cliffs ( $\mathrm{H}_{\mathrm{t}} \mathrm{C} 1$ and $\mathrm{C} 2$ ) on the south coast where the distance between the coastline and reef edge is about $700 \mathrm{~m}$ (see the white arrow in Fig. 10). This implies that $\mathrm{H}_{\mathrm{t}} \mathrm{C} 1$ and $\mathrm{C} 2$ have never experienced tsunami(s) higher than $2.1 \mathrm{~m}$, and have not yet fallen even though the heights of tsunamis are almost the same everywhere before the reef crest around Kuro-shima. We infer that the heights of tsunamis reaching the coasts decrease with increasing distance between the coastlines and the edge of the offshore reefs. The height of the reef crest may also affect the tsunami height, but we do not consider this further here.

Fringing reefs do not necessarily act as an effective barrier against invading tsunamis if fringing reefs develop discontinuously. Some wave-induced blocks are seen at south-eastern coasts although the distance between the coastline and offshore reef edge is the greatest in Kuro-shima. This appears to be due to the cutting of the fringing reefs by the fault running in the NW-SE direction. Surging tsunamis from the Pacific ocean could be concentrated at the gap. This phenomenon is often referred to as the "channelling effect". Overall, reefs will always absorb some of the wave energy, but, by channelling the water masses, the concentrated impact could be greater on coastal stretches with nearby reefs (Cochard et al., 2008). Our observation is consistent with records by Fernando et al. (2005) and Marris (2005), who reported the effects of channelling on the heights of tsunamis in the 2004 tsunami in Sri Lanka. Also, the height of tsunamis would be amplified, not reduced, during propagation through narrow paths or patchy reefs in the Great Barrier Reef (Nott, 1997).

\section{Conclusion}

This study showed stability analysis models to evaluate the cliff collapses due to extreme waves. We determined the distribution of the blocks caused by cliff collapses due to 
tsunamis, by means of stability analysis. Comparison of the distributions of blocks caused by tsunamis and by gravitational processes shows that two factors influence the height of tsunamis that reach the coasts. One factor is the distance between the coastline and reef edge. The heights of tsunamis reaching coasts decrease with increasing distance between the coastline and offshore reef edge. The other factor is continuity in the fringing reefs and their development. The height of tsunamis invading through the coral reef must have been constant or amplified by deep and narrow gaps, known as the channelling effect. Tsunamis which passed through the gap were able to reach the coasts without any loss of height and induce collapses of coastal cliffs. Therefore, broad and continuous "modern" fringing reefs may act as an effective barrier against tsunamis to collapse coastal cliffs, i.e., "ancient" fringing reefs.

\section{Author details}

Tetsuya Kogure

Research Institute of Innovative Technology for the Earth, Japan

Yukinori Matsukura

University of Tsukuba, Japan

\section{References}

Cochard, R., Ranamukhaarachchi, S.L., Shivakoti, G.P., Shipin, O.V., Edwards, P.J. \& Seeland, K.T. 2008. The 2004 tsunami in Aceh and Southern Thailand: A review on coastal ecosystems, wave hazards and vulnerability. Perspectives in Plant Ecology, Evolution and Systematics, Vol. 10, pp. 3-40.

Fernando, H.J.S., Mendis, S.G., McCulley, J.L. \& Perera, K. 2005. Coral poaching worsens tsunami destruction in Sri Lanka. EOS Transactions, Vol. 86, pp. 301-304.

Hom-ma, M.\&Horikawa, K. 1964. Wave force against sea wall, Proceedings of 9th Conference on Coastal Engineering, Reston, 1964.

Ikeno, M., Matsuyama, M.\&Tanaka, H. 1998. Shoaling and soliton fission of tsunami on a shelf and wave pressure for tsunami-resistant design of breakwater by large wave flume-experiments, Proceedings of 45th Japanese Coastal Engineering Conference, Akita, November, 1998 (in Japanese).

Imamura A. 1938. On the earthquake zone of the Ryukyus and the large Meiwa Tsunami. Zishin, Vol. 10, pp. 431-450 (in Japanese).

Kato Y. \& Kimura M. 1983. Age and origin of so-called "Tsunami-ishi", Ishigaki Island, Okinawa Prefecture. The Geological Society of Japan, Vol. 89, pp. 471-474 (in Japanese).

Kato, Y. \& Matsuo, K. 1998. Estimation of tsunami behavior based on identification of original tsunami boulders: an example in Kuroshima Island. Kaiyo Monthly, Vol. 15, pp. 183-187 (in Japanese).

Kogure, T., Aoki, H., Maekado, A., Hirose, T. \& Matsukura, Y. 2006. Effect of the development of notches and tension cracks on instability of limestone coastal cliffs in 
the Ryukyus, Japan. Geomorphology, Vol. 80, pp. 236-244. DOI. 10.1016/ j.geomorph.2006.02.012

Kogure, T. \& Matsukura, Y. 2010a. Critical notch depths for failure of coastal limestone cliffs: Case study at Kuro-shima Island, Okinawa, Japan. Earth Surface Processes and Landforms, Vol. 35, No. 9, pp. 1044-1056.

Kogure, T. \& Matsukura, Y. 2010b. Instability of coral limestone cliffs due to extreme waves. Earth Surface Processes and Landforms, Vol. 35, No. 11, pp. 1357-1367.

Kogure, T. \& Matsukura, Y. 2011. Effect of vertical joints on the planar shape of fallen blocks in coastal cliff collapses at Kuro-shima, Okinawa, Japan. Transactions, Japanese Geomorphological Union, Vol. 32, pp. 15-28.

Kono, T. \& Tsukayama, S. 1980. Wave transformation on reef and some consideration on its application to field. Coastal Engineering in Japan, Vol. 23, pp. 45-57.

Maekado, A. 1991. Recession of coastal cliff made of Ryukyu Limestone: Arasaki coast, southern end of Okinawa Island, Japan. Bulletin of the Okinawa Geographical Society, Vol. 3, pp. 63-70.

Marris, E. 2005. Tsunami damage was enhanced by coral theft. Nature, Vol. 406, pp. 1071.

Munk, W. \& Sargent, M.C. 1948. Adjustment of Bikini Atoll to ocean waves. Transactions of American Geophysical Union, Vol. 29, pp. 855-860.

Nakata, T. \& Kawana, T. 1995. Historical and Prehistorical large tsunamis in the southern Ryukyus, Japan. In: Tsunami: Progress in Prediction, Disaster Prevention and Warning, Tsuchiya, Y., \& Shuto, N. (Eds.), pp. 211-222, Kluwer Academic Publishers, ISBN: 978-07923-3483-5, Netherlands.

Nakaza, E., Tsukayama, M., Hino, M. \& Ohosiro, T. 1988. A study on waveforces induced by wave groups, Proceedings of 35th Japanese Coastal Engineering Conference, Ehime, November, 1988 (in Japanese).

Nott, J. 1997. Extremely high-energy wave deposits inside the Great Barrier Reef, Australia: determining the cause - tsunami or tropical cyclone. Marine Geology, Vol. 141, pp. 193207.

Roberts, H.H. \& Suhayda, J.N. 1983. Wave-current interactions on a shallow reef (Nicaragua, Central America). Coral Reefs, Vol. 1, pp. 209-214.

Shibayama, T., Okayasu, A., Wijayaratna, N., Sasaki, J., Suzuki, T. \& Jayaratne, R. 2005. The 2004 Sumatra Earthquake Tsunami, tsunami field survey in southern part of Sri Lanka, Proceedings of 52th Japanese Coastal Engineering Conference, Aomori, November, 2005 (in Japanese).

Timoshenko, S.P. \& Gere, J.M. 1978. Mechanics of Materials, Van Nostrand Reinhold, New York.

Tjia, H.D. 1985. Notching by abrasion on a limestone coast. Zeitschrift für Geomorphologie N. F., Vol. 29, pp. 367-372. 